\title{
Preparation of Shape Memory Alloys (Al-Cu-Mn) by Nd:YAG Laser and Study of Physical Properties
}

\author{
Laith N. Abbas* and RaWA K. Ibrahim \\ Laser and Optoelectronic Research Center, Directorate of Materials Research, \\ Ministry of Science and Technology, Al-Jaderiya st., 00964, Baghdad, Iraq \\ Doi: 10.12693/APhysPolA.140.350 \\ *e-mail: laith_nadhim2000@yahoo.com
}

\begin{abstract}
The preparation of smart alloys for most applications in electronics and medicine is a major challenge, especially for use as dental materials, or spinal and arterial catheters. In this research, the $\mathrm{Al}-\mathrm{Cu}-$ Mn smart alloy was prepared with a pulsed Neodymium:YAG laser, with maximum energy of $1.6 \mathrm{~J}$ and a $10 \mathrm{~ns}$ pulse width, using different numbers of pulses and energies. The properties of this alloy were studied with Fourier transform infrared spectroscopy, X-ray fluorescence, X-ray diffraction, and scanning electron microscopy. The three metals, i.e., copper, aluminum, and manganese were mixed in equal weight proportions. The best $\mathrm{Al}-\mathrm{Cu}-\mathrm{Mn}$ alloy was obtained for laser shots with $1300 \mathrm{~mJ}$ energy.

topics: shape memory, laser annealing
\end{abstract}

\section{Introduction}

Shape Memory Alloys (SMAs) are metallic alloys which have amazing properties, i.e., pseudo elasticity and the ability to recover their original shape after quasi plastic deformation $[1,2]$. The first study for the SMA alloy was carried out in 1932 by A. Ölander [1-4] who found out the pseudoelasticity properties of gold-cadmium alloy. In 1949, the memory effect of gold-cadmium was reported by Kurdjumov \& Kandros [5]. In 1962-1963, Naval Ordnance Laboratory discovered the shape memory effect in a nickel-titanium alloy [6], which was a breakthrough in the field of shape memory alloys at that time. Then, in 1970-1980, the alloy was commercialized for use in medical applications. In mid 1990s [7-9], the memory metals began to be used widely in medicine and other applications [9]. So far, the SMA alloys are exploited in many fields of life such as eyeglass frames, cellular phone antennae, bra under wires, medical devices, orthodontic arches, robots, anti-scald devices, fire sprinklers, deep fryers and other household appliances. They also prevent structural damage to bridges and buildings $[10-16]$.

Shape memory alloys are a peerless class of metal alloys that are able to overcome apparent stable strains when heated above a given temperature. The shape memory alloys can exist in two phases [10, 11]: (i) the high temperature phase, called austenite (named after William
Chandler Austen [10]), and (ii) the low temperature phase, called martensite (named after Adolf Martens [12-18]).

In general, metals may be described according to their physical properties such as conductivity, ductability, malleability, and strength. There are other properties that are required for SMAs, such as the anthropomorphic qualities of memory and trainability. SMAs exhibit the shape memory effect when they are plastically deformed at one temperature and made to recover their original shape entirely when heated to a higher temperature. In restoring the original shape, the alloys will generate dislocations or build up strain. There are many alloys that show both.

Shape memory alloys can solve a large variety of problems, such as virtually leak proof couplings for pneumatic or hydraulic lines $[19,20]$. The alloys have also been exploited in mechanical and electromechanical control systems, medical and dental applications due to the response to small and repeated changes in temperature $[7,20]$.

There are some materials that exhibit shape memory effects known to date [20]:

- silver-cadmium 44/49 at.\% Cd,

- gold-cadmium 46.5/50 at.\% Cd,

- copper-aluminum-nickel 14/14.5 wt\% $\mathrm{Al}$ and $3 / 4.5 \mathrm{wt} \% \mathrm{Ni}$,

- copper-tin $\approx 15$ at.\% Sn, 
- copper-zinc 38.5/41.5 at.\% Zn,

- copper-zinc-X (X = silicon, aluminum, tin),

- iron-platinum $\approx 25$ at.\% Pt,

- manganese-copper 5/35 at.\% Cu,

- nickel-titanium 50 at.\% Ti.

Among them, only nickel-titanium and $\mathrm{Cu}$-based alloys are commercially exploited. This work deals with the preparation of an AlCuMn alloy and the study of its structural and optical properties.

\section{Materials and methods}

In this work, the AlCuMn alloy was prepared in the following steps.

The first step was mixing of the $\mathrm{Cu}, \mathrm{Al}$, and Mn nanopowders in weight ratio 1:1:1. Figure 1 shows the three materials before grinding. In the second step the AlCuMn mixture was compressed into a disk with a diameter of $5 \mathrm{~cm}$ under the weight of 5 ton (see Fig. 2). In the third step, the compressed disk was heated at $300^{\circ} \mathrm{C}$ for $1 \mathrm{~h}$. The heat treatment is very important for homogenization of the nanomaterials, as shown in Fig. 3.

The last step is the laser treatment (annealing) of the compressed disk with the $1064 \mathrm{~nm}$ wavelength of the Nd:YAG laser. The pulse duration was $10 \mathrm{~ns}$ and the pulse energies ranged from $1 \mathrm{~J}$ to $1.6 \mathrm{~J}$. Five pulses were applied (see Fig. 4).
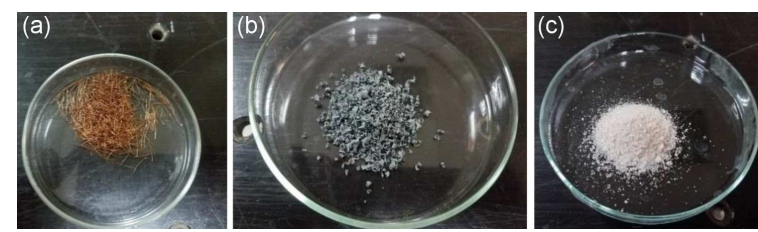

Fig. 1. (a) Copper, (b) aluminum, and (c) manganese components of the alloy before grinding.

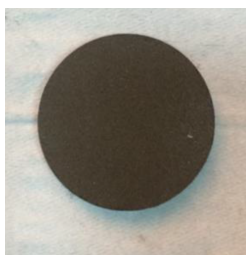

Fig. 2. The AlCuMn alloy disk.

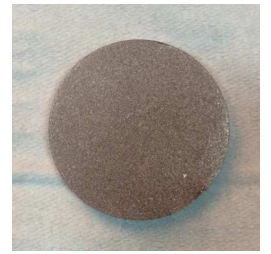

Fig. 3. The AlCuMn disk after heat treatment.

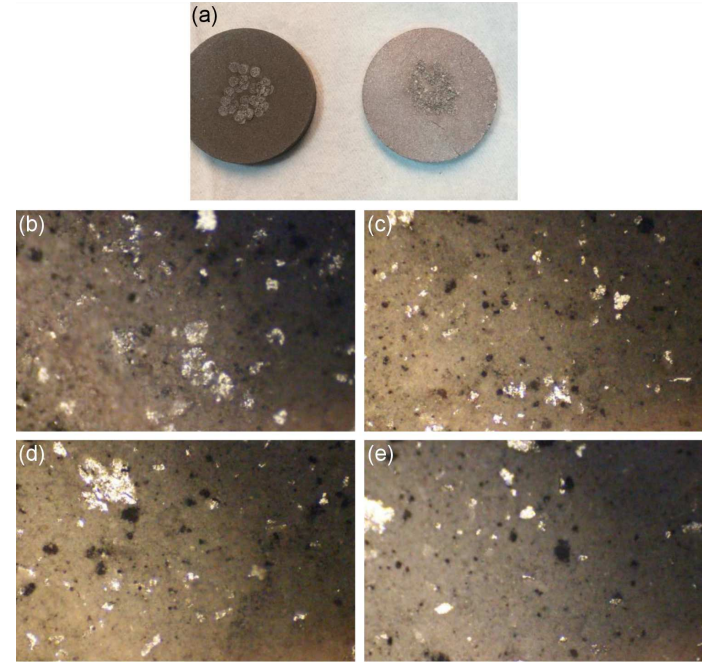

Fig. 4. (a) Photographs of the alloy disks after laser treatment. (b-e) Optical microscope images of the parts of the disk shot with pulse energies of (b) $1 \mathrm{~J}$, (c) $700 \mathrm{~mJ}$, (d) $520 \mathrm{~mJ}$, and (e) $259 \mathrm{~mJ}$.

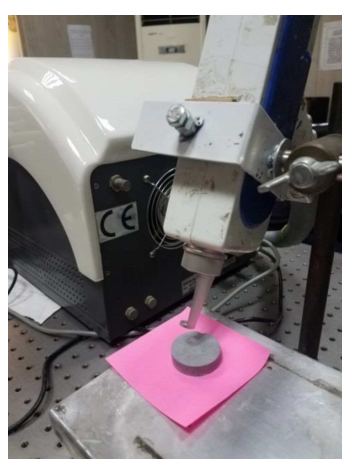

Fig. 5. The Nd:YAG laser used to process the AlCuMn compressed disk.

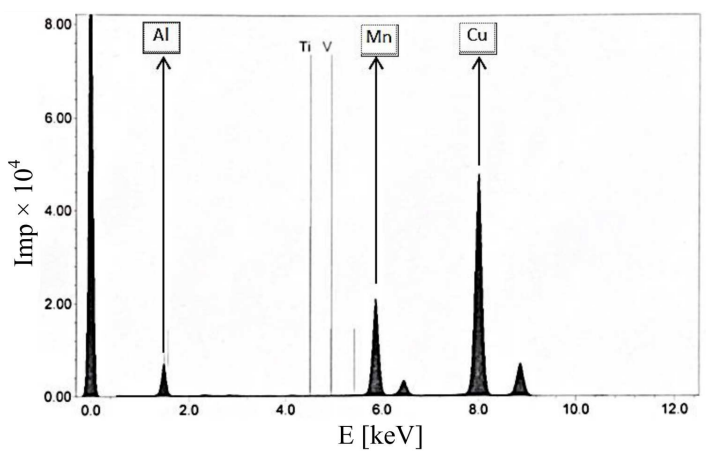

Fig. 6. XRF spectrum of the AlCuMn alloy.

Figure $4 \mathrm{a}$ shows the photograph of the compressed disk of AlCuMn. Figures $4 \mathrm{~b}$ to $4 \mathrm{e}$ present the optical microscopic images of the compressed disk of AlCuMn. Figure 5 shows the Neodymium:Yag (Nd:YAG) laser used to shoot the compressed disk. 

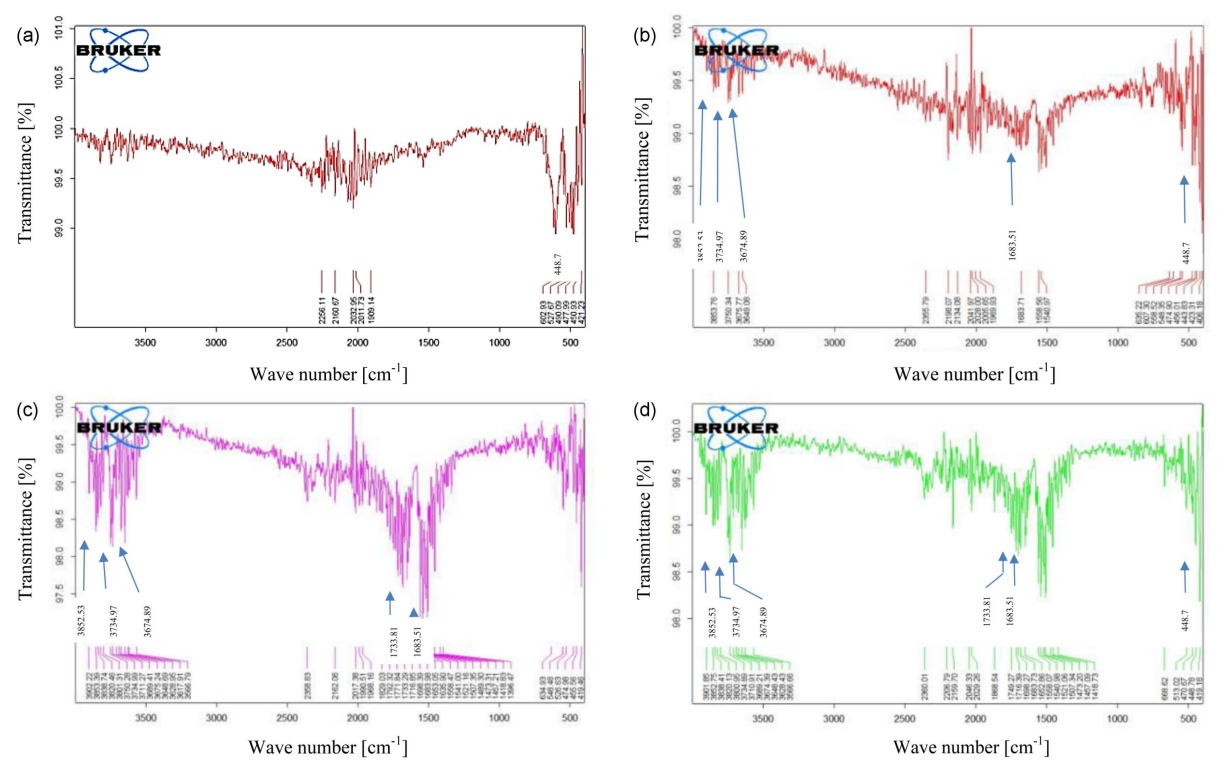

Fig. 7. FTIR spectra of the AlCuMn alloy (a) without laser annealing, annealed with (b) $1000 \mathrm{~mJ}$, (c) $1300 \mathrm{~mJ}$, (d) $1600 \mathrm{~mJ}$ laser energies.
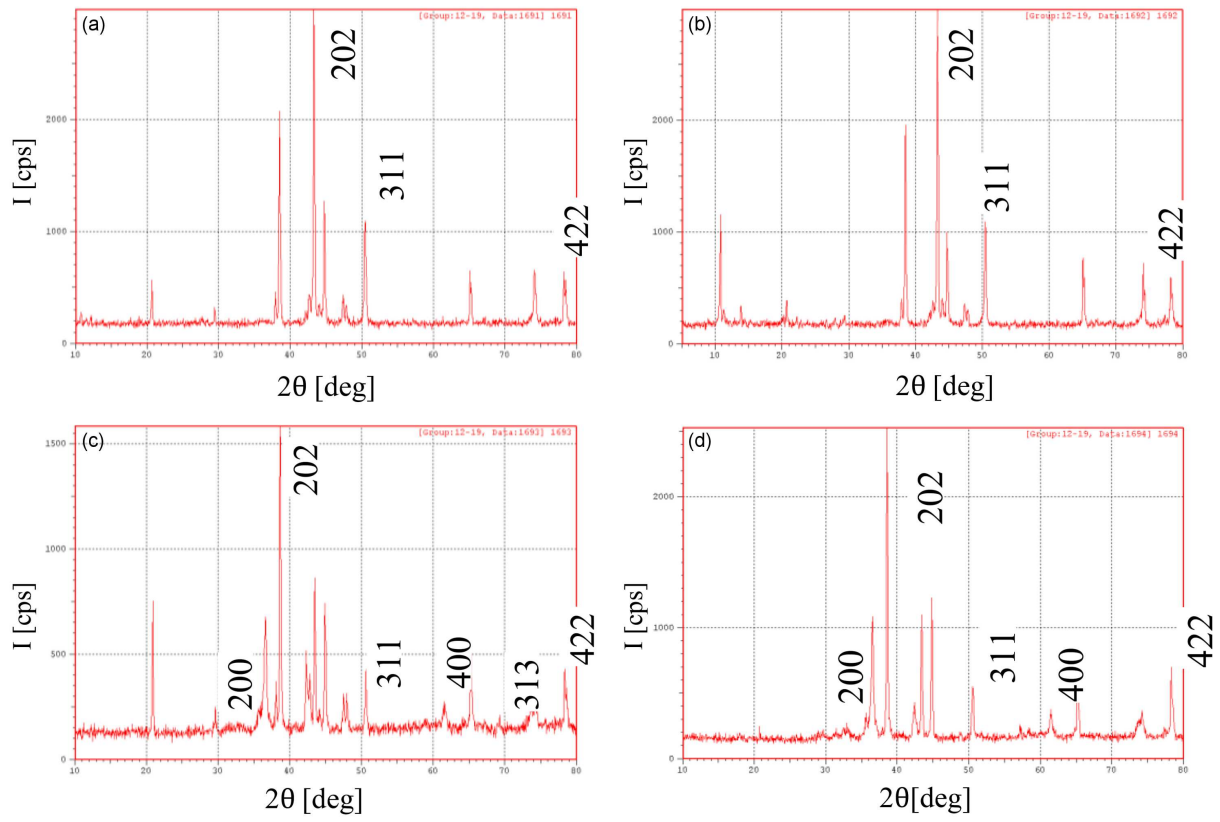

Fig. 8. The XRD patterns of the AlCuMn alloy (a) without laser annealing, for sample treated with (b) $1000 \mathrm{~mJ}$, (c) $1300 \mathrm{~mJ}$, and (d) $1600 \mathrm{~mJ}$ laser pulse energy.

In order to assess the purity of materials comprising the AlCuMn alloy X-ray fluorescence (XRF) measurements were the conducted. The X-ray diffraction (XRD) was used to identify the structure of the prepared alloy. The Fourier Transform Infrared spectroscopy (FTIR) was used to investigate the vibrational frequencies of the materials in the alloy as well as the absorption bands, and these are characteristic for each type of chemical bond. Surface morphology was investigated with a scanning electron microscope (SEM).

\section{Results and discussion}

The XRF results show that the AlCuMn disk (see Fig. 6) contains $\mathrm{Cu}, \mathrm{Al}$, and $\mathrm{Mn}$ elements at average atomic percentages of $73.25 \%, 10.7 \%$, and $13.97 \%$, respectively. The FTIR analysis of the $\mathrm{AlCuMn}$ disk shows additional peaks at wave numbers of 443.96, 1683.51, 1733.21, 3674.89, 3734.97, and $3852.53 \mathrm{~cm}^{-1}$ (see Fig. 7), which may be related to adsorbed air particles bound to $\mathrm{Al}, \mathrm{Cu}$, and $\mathrm{Mn}$ on the alloy surface. The changes of the 

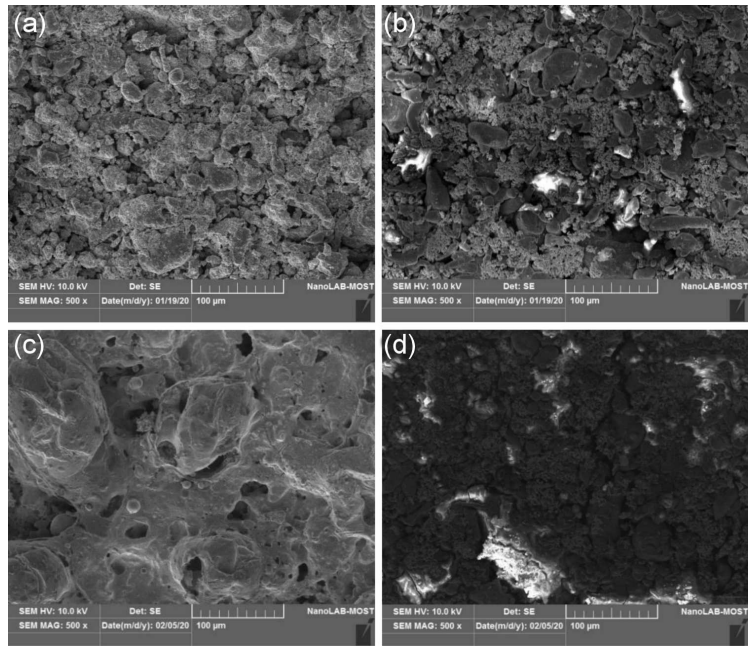

Fig. 9. SEM images of AlCuMn alloy (a) without laser annealing, annealed with (b) $1000 \mathrm{~mJ}$ laser pulse energy, (c) $1300 \mathrm{~mJ}$ laser pulse energy, (d) $1600 \mathrm{~mJ}$ laser pulse energy. The magnification in all images was $500 \times$ with scale $100 \mu \mathrm{m}$.

structure induced by each pulse energy are demonstrated by the XRD patterns shown in Fig. 8. The grain size of the AlCuMn alloy, calculated based on Scherer's equation, was $49.4 \mathrm{~nm}$ for the sample without laser annealing, $46.7 \mathrm{~nm}$ for the sample shot with $1000 \mathrm{~mJ}$ laser energy, $45.023 \mathrm{~nm}$ for $300 \mathrm{~mJ}$, and $45.85 \mathrm{~nm}$ for $1600 \mathrm{~mJ}$. The Miller indices in the figure indicate peaks belonging to the $\mathrm{AlCuMn}$ phase. They appear after annealing with $1300 \mathrm{~mJ}$ and $1600 \mathrm{~mJ}$ laser energy. The reflexes of the (200), (202), (311), (400), (313), and (422) planes occur at angles $30.4^{\circ}, 43^{\circ}, 50.9^{\circ}, 62.4^{\circ}, 68.7^{\circ}$, and $78.8^{\circ}$, respectively.

The SEM images of the AlCuMn alloy which show the surface morphology and the roughness are given in Fig. 9. The sample that was annealed with laser energy of $1300 \mathrm{~mJ}$ (see Fig. 9c) shows the optimal result because it is the most homogenous and the surface is smoother.

\section{Conclusions}

The smart shape memory alloy CuAlMn was successfully prepared in this work using the Nd:YAG laser with energy in the range of $1-1.6 \mathrm{~J}$ for five pulses. The FTIR spectra give a simple indication for new peaks appearing (pointed with blue arrows in Fig. 7) at high energy 1.6 J of Nd:Yag Laser used. The SEM shows that $1.3 \mathrm{~J}$ is the best pulse energy to prepare the SMA.

\section{References}

[1] T.W. Duerig, MRS Online Proceedings Library 360, 497 (1994).

[2] M.R. da Silva, P. Gargarella, W. Wolf, T. Gustmann, C.S. Kiminami, S.Pauly, J. Eckert, C. Bolfarini, Materials Research 21, 13 (2018).

[3] A. Lago, D. Trabucco, A. Wood, in: Damping Technologies for Tall Buildings, Elsevier, 2019, Ch. 4, p. 107.

[4] I. Stachiv, E. Alarcon, M. Lamac, Metals 11, 415 (2021).

[5] L.M. Schetky, Scientific American 241, 74 (1979).

[6] G.B. Kauffman, I. MAYO, The Chemical Educator 2(2), 1 (1997).

[7] E. Chappel, D.D. Fillon, in: Drug Delivery Devices and Therapeutic Systems, Elsevier, 2021, Ch. 3, p. 31.

[8] K. Hu, K. Rabenorosoa, M. Ouisse, Front. Robot. AI 8, 202 (2021).

[9] L. Petrini, F. Migliavacca, J. Metall. 2011, 501483 (2011).

[10] X. Huang, G.J. Ackland, K.M. Rabe, Nat. Mater. 2, 307 (2003).

[11] F.R. Milhorato, E.M. Mazzer, Mater. Sci. Eng. A 232, 753 (2019).

[12] J. Daudpoto, A. Dehghani-Sanij, R. Richardson, Sage J. 48, 285 (2015).

[13] A. Concilio, V. Antonucci, E. Sacco, V. Antonucci, L. Lecce, Shape Memory Alloy Engineering: For Aerospace, Structural and Biomedical Applications, 2nd Ed., Elsevier, 2021.

[14] A. Tabrizikahou, M.H.-Nyarko, M. Kuczma, S. Lozančić, Materials 14, 4480 (2021).

[15] E.M. Mazzer, C.S. Kiminami, C. Bolfarini, R.D. Cava, W.J. Botta, P. Gargarella, F. Audebert, M. Galano, Mater. Sci. Eng. A 663, 64 (2016).

[16] E.M. Mazzer, P. Gargarella, C.S. Kiminami, J. Alloys Compd. 723, 841 (2017).

[17] N. Babacan, S. Pauly, T. Gustmann, Mater. Des. 203, 109625 (2021).

[18] D. Gera, J. Santos, C.S. Kiminami, P. Gargarella, Trans. Nonferr. Metal Soc. China 30, 3322 (2020).

[19] N. Babacan, S. Pauly, T. Gustmann, Mater. Des. 203, 109625 (2021).

[20] Z. Wang, M. Wang, Y. Li, H. Xiao, H. Chen, J. Geng, X. Li, D. Chen, H. Wang, Mater. Des. 203, 109618 (2021). 